\title{
A laboratory study of ploughing
}

\author{
Marie ROUSSELOT, ${ }^{1 *}$ Urs H. FISCHER ${ }^{1,2}$ \\ ${ }^{1}$ Laboratory of Hydraulics, Hydrology and Glaciology (VAW), ETH-Zürich, CH-8092 Zürich, Switzerland \\ E-mail: marie.rousselot@meteo.fr \\ ${ }^{2}$ Department of the Environment and Heritage, Australian Antarctic Division and Antarctic Climate and Ecosystems CRC, \\ Private Bag 80, Hobart, Tasmania 7001, Australia
}

\begin{abstract}
A new laboratory device is used to investigate the resistance to clast ploughing at the base of glaciers. In experiments in which a ploughing tip is dragged at different velocities and effective normal stresses through water-saturated sediment from Unteraargletscher, Switzerland, pore pressures above and below the hydrostatic level develop around the tip. The absolute magnitude of these nonhydrostatic pore pressures increases with the ploughing velocity but remains small compared to the sediment yield strength, so that the pore pressures do not significantly weaken the sediment. The shear stress on the tip is independent of the velocity but scales with the applied effective normal stress, in agreement with a Coulomb-plastic behavior of the sediment. The results indicate that, depending upon position close to the object, both sediment compaction and dilation can influence the pore-pressure distribution and thus the sediment yield strength. Comparison with other studies of clast ploughing suggests that the significance of sediment weakening in front of ploughing clasts may depend on the relative magnitudes of the non-hydrostatic pore pressures. Therefore, depending on the dominant porepressure response of the deforming sediment, clast ploughing may have the potential to either trigger ice-flow instabilities or stabilize glacier motion.
\end{abstract}

\section{INTRODUCTION}

Early observations of layers of deformed sediment up to several meters thick in the forefield of retreating glaciers (e.g. Van der Meer, 1987) and beneath glacier margins (Boulton and Hindmarsh, 1987) led to the recognition that the deformation of subglacial sediment can contribute considerably to the overall motion of a glacier. More recently, field investigations using modern geophysical techniques have indicated that, depending on the amount of basal shear stress transmitted across the ice-bed interface (e.g. Alley and others, 1987), deforming beds may be involved in ice-flow instabilities such as glacier surging (Truffer and others, 2001; Harrison and Post, 2003) and fast ice streaming (Kamb, 2001; Alley and others, 2004; Ó Cofaigh and others, 2005). However, the hydromechanical factors that control the degree of ice-bed coupling and thus the basal shear stress resisting the flow of soft-bedded glaciers are poorly understood. In particular, the process known as ploughing, where clasts that protrude into the glacier sole are dragged through the upper layer of the sediment bed (Brown and others, 1987; Alley, 1989), remains largely unexplored. This process may have fundamental implications for the basal motion of fast-flowing glaciers because excess pore pressure that weakens the sediment may be generated by sediment compression down-glacier from the ploughing clasts and lead to a significant reduction in the basal resistive shear stress (Iverson and others, 1995; Fischer and others, 2001; Thomason and Iverson, 2003). Field investigations of the conditions that promote excess pore-pressure generation during clast ploughing are sparse (Fischer and others, 2001; Rousselot and Fischer, 2005) and their interpretation is complicated by the variability of subglacial water pressure, sliding velocity and sediment properties. For these reasons,

*Present address: Météo-France/Centre d’Etudes de la Neige, 1441 rue de la Piscine, 38406 Saint-Martin-d'Hères Cedex, France. this study was initiated using a new laboratory apparatus (Rousselot and others, in press) to perform ploughing experiments. In these experiments, a ploughing tip is dragged at different velocities through a glacial sediment subject to various effective normal stresses. Pore pressure is measured in the vicinity of the tip, and its influence on the shear stress resisting the tip motion is studied. The results are compared to previous field and laboratory studies of ploughing (Thomason and Iverson, 2003; Rousselot and Fischer, 2005) and potential implications of clast ploughing for glacier dynamics are discussed.

\section{APPARATUS AND PROCEDURE}

Ploughing experiments were performed with a new laboratory device of large dimensions, dubbed the rotary ploughing device (Rousselot and others, in press), by dragging an instrumented tip through sediment under glacially relevant conditions (Fig. 1). Water-saturated sediment is contained in a cylinder $0.58 \mathrm{~m}$ in diameter, and is subject to a normal stress by suspending dead weights from a lever arm with a system of pulleys. The lever arm presses on a platen through a vertical shaft that sits in a square mounting to inhibit rotation while still allowing vertical motion (Fig. 1a). The sediment pore-water is in hydraulic communication with an external water reservoir which is open to the atmosphere, so that the normal stress applied on the sediment corresponds to the effective stress under fully drained conditions. A $140 \mathrm{~m}$ long, $32 \mathrm{~mm}$ diameter steel rod terminated by a conical tip is set $110 \mathrm{~mm}$ from the cylinder wall into the platen and protrudes $40 \mathrm{~mm}$ into the sediment (Fig. 1b). As the sediment chamber is rotated by a motor, the tip is dragged through the sediment. The ploughing rod is permitted to flex along its entire length, with the point where the tip is fitted via the mounting into the platen acting as a fulcrum. The resulting elastic bending of the rod is registered with strain gauges and converted into a force and an azimuth with the use of a 


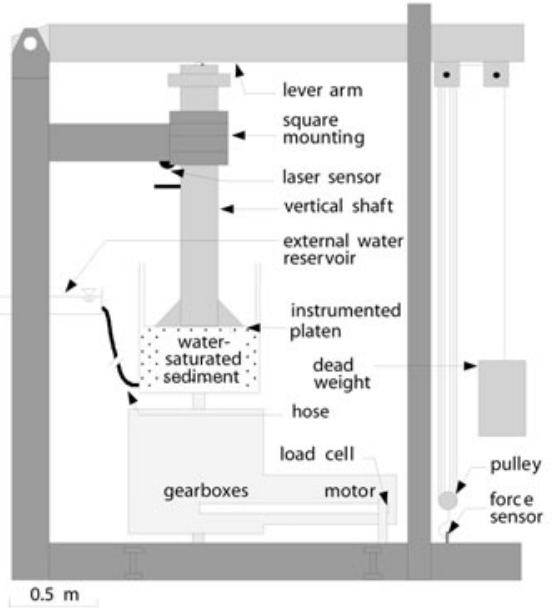

b

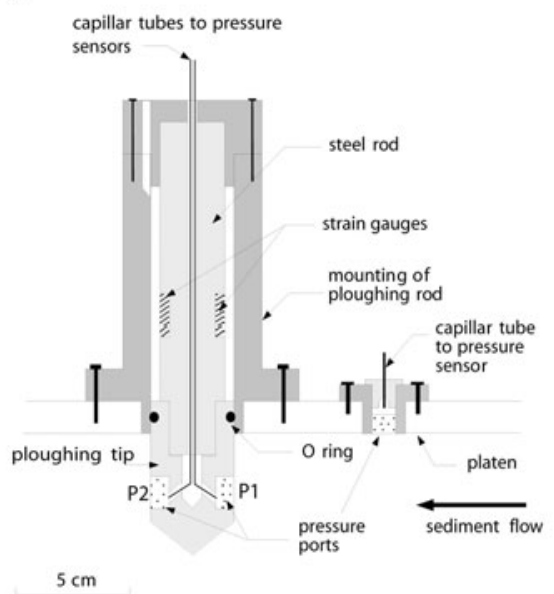

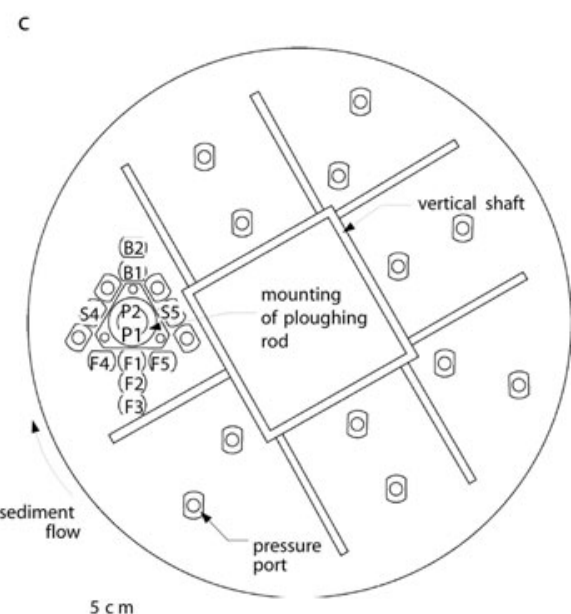

Fig. 1. Schematic diagrams of the rotary ploughing device. (a) Side view showing the support frame (dark gray), lever-arm/pulley system (mid-tone gray), drive mechanism (light gray) and cylinder containing the sediment. (b) Flow-parallel view of the ploughing tip and a pressure port on the platen. (c) Plan view of the platen showing the position of the pressure ports. During ploughing experiments, the porewater pressure is measured at the pressure ports labelled P1, P2 (on the tip) and F1, F2, F3, F4, F5, S4, S5, B1, B2 (on the platen), while ports not used for measurements are closed hermetically by a plastic cap.

laboratory calibration, following the description of Fischer and Clarke (1994). Pore pressures in the sediment in the vicinity of the tip are measured on the lee and stoss sides of the tip and on the platen (Fig. 1b and c).

Prior to an experiment, the sediment is saturated with water and poured into the sediment chamber. The platen is subsequently lowered onto the sediment and a normal stress is imposed for consolidation. After full consolidation,

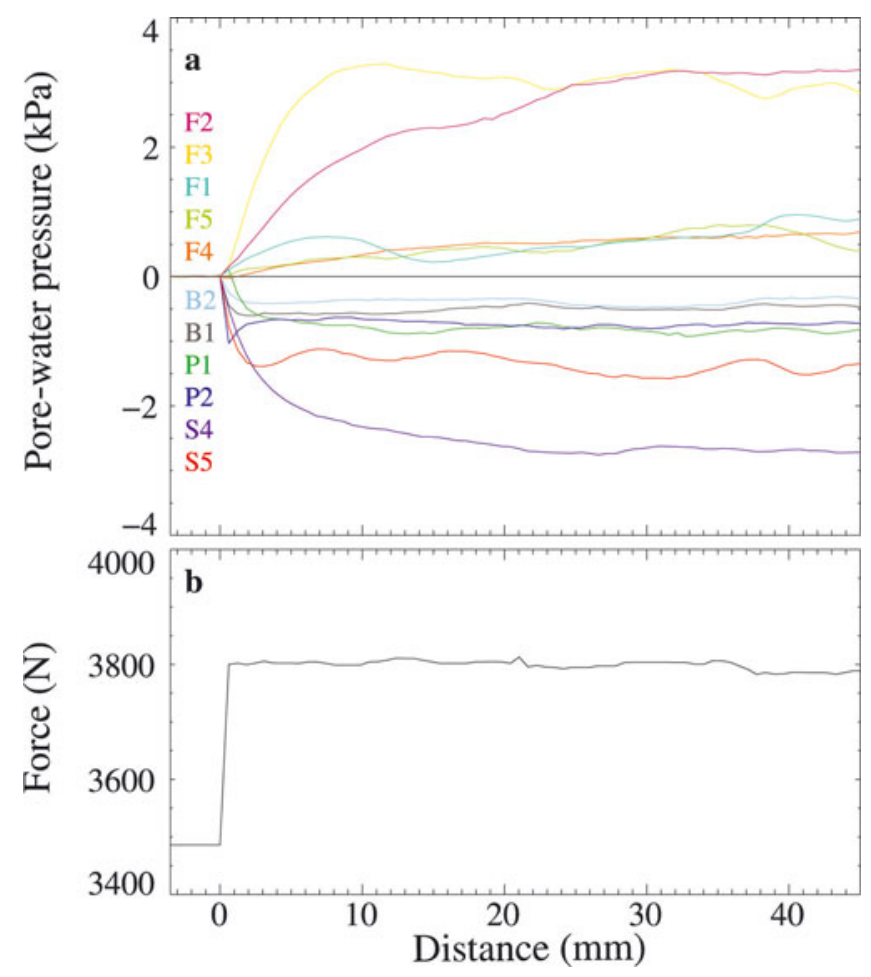

Fig. 2. Results of a ploughing experiment showing records of (a) pore-water pressure and (b) drag force as a function of the distance ploughed by the tip. In this experiment, $P_{\mathrm{e}}=75 \mathrm{kPa}$ and the ploughing velocity was $5 \mathrm{~m} \mathrm{~d}^{-1}$. The positions of the pressure ports are shown in Figure 1c. The hydrostatic water pressure was subtracted from the pressure records. ploughing of the sediment is started by rotating the sediment chamber and corresponding changes in drag force on the tip, azimuth and pore pressure are recorded. A detailed description of the apparatus and the experimental procedure is given in Rousselot and others (in press).

Ploughing experiments were carried out for a range of normal stresses typical for effective stresses under glaciers (50-200 kPa) and ploughing speeds that cover typical glacial velocities $\left(1-16 \mathrm{~m} \mathrm{~d}^{-1}\right)$ using a sediment $\sim 0.2 \mathrm{~m}$ thick. The sediment, from which particles larger than $0.25 \mathrm{~mm}$ were removed, was collected in the recently deglaciated forefield of Unteraargletscher, Switzerland. The sediment thus obtained contains $70 \%$ sand, $25 \%$ silt and $5 \%$ clay and has a diffusivity of $\sim 5 \times 10^{-5} \mathrm{~m}^{2} \mathrm{~s}^{-1}$ (Rousselot and others, in press). The friction angle of this sediment, estimated from its grain-size distribution (Lang and others, 2003), is $\sim 35^{\circ}$. Decrease in sediment thickness observed during preliminary experiments is probably due mainly to sediment loss and friction inherent to the device (Rousselot and others, in press). This problem can be partially eliminated by first overconsolidating the sediment. Nevertheless, to obtain results independent of the degree of consolidation, the sediment is ploughed prior to an experiment. Subsequently, an experiment is started when the pore pressure has returned to its steady value. We can reasonably assume that these conditions represent those existing over large portions of a glacier bed where sediment has been deformed in the past.

\section{RESULTS}

\section{Pore pressure}

Typical records of pore pressure during a ploughing experiment are shown in Figure 2a. Steady pore pressures are attained after a few centimeters of tip displacement, with pore pressures above and below the hydrostatic value (Fig. 2a). These non-hydrostatic pore pressures have been interpreted by Rousselot and others (in press) to result from two distinct effects. Excess pore pressure develops in front of the tip (at F1-F5) because the sediment there is compressed at a rate which is greater than the rate of pore-water pressure 

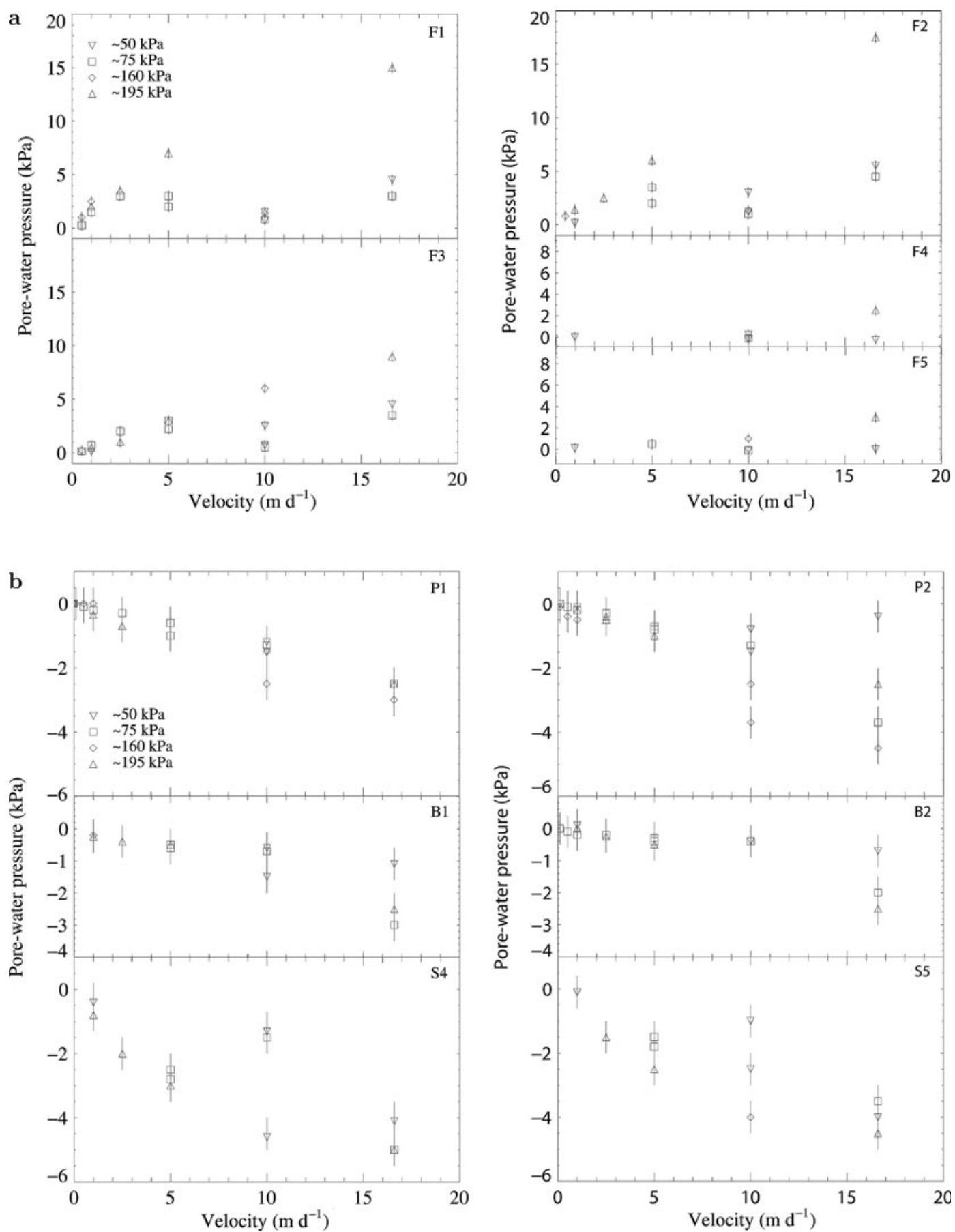

Fig. 3. Pore-water pressure recorded at (a) F1-F5 (excess pore-water pressure) and (b) P1, P2, B1, B2, S4, S5 (pore-water pressure below the hydrostatic value) as a function of ploughing velocity for applied effective normal stresses of $\sim 50 \mathrm{kPa}(\nabla), \sim 75 \mathrm{kPa}(\square), \sim 160 \mathrm{kPa}(\diamond)$ and $\sim 195 \mathrm{kPa}(\triangle)$. The positions of the pressure ports are shown in Figure 1c. The error bars correspond to the $\pm 0.5 \mathrm{kPa}$ accuracy of the pressure sensors. The hydrostatic water pressure was subtracted from the pressure measurements.

diffusion. Compression of the sediment in front of the tip also causes local overconsolidation there, so the overconsolidated sediment tends to dilate as it shears past the tip. This effect results in pore pressures below the hydrostatic value on either side (at S4 and S5) and on the leading edge (at P1) of the tip.

Results of experiments performed at different velocities and normal stresses typical for fast-flowing glaciers are presented in Figures 3 and 4. Figure $3 a$ indicates that the magnitude of the excess pore pressure increases with the ploughing velocity and thus with the rate of sediment compression. Similarly, larger absolute magnitudes of sub-hydrostatic pore pressure are associated with larger ploughing velocities and thus with larger rates of dilatant shearing (Fig. 3b). This latter effect is also observed in each individual experiment, with a pore pressure at $\mathrm{S} 4$ that is systematically lower than that at $\mathrm{S} 5$, because the circular geometry of the apparatus results in shear rates that are larger at S4 than at S5 (Figs 1c, $2 \mathrm{a}$ and $3 \mathrm{~b}$ ). Excess pore pressure seems to be preferentially generated in the direction of motion in front of the tip, as suggested by pore-pressure values that are systematically lower at F4 and F5 than those at F1-F3 (Fig. 3a). The distance of the pore-pressure maximum in front of the tip increases with increasing ploughing velocity (Fig. 4), 


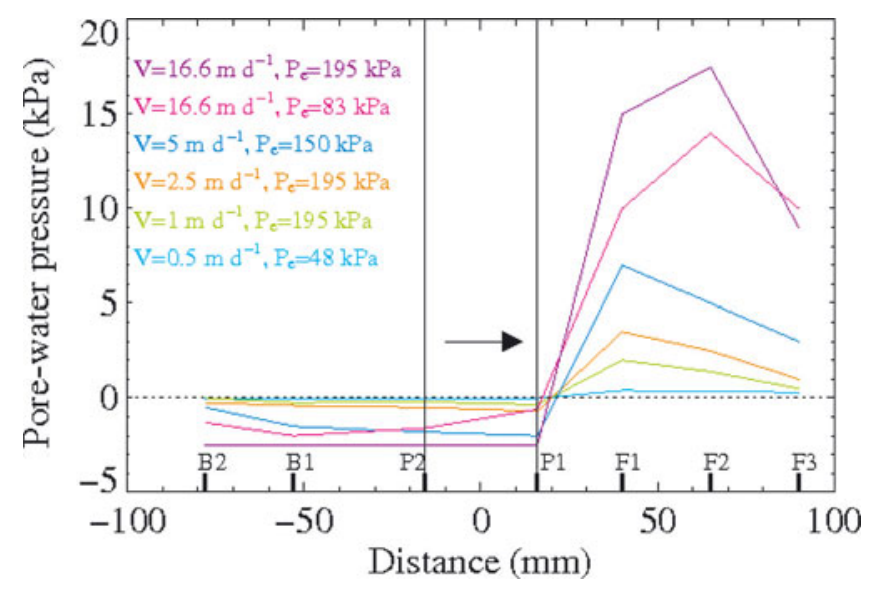

Fig. 4. Pore-pressure distribution behind and in front of the ploughing tip along the direction of motion for different velocities, $V$, and applied effective normal stresses, $P_{\mathrm{e}}$. The vertical black lines show the position of the ploughing tip, and the arrow indicates the direction of relative motion. The hydrostatic water pressure was subtracted from the pressure measurements. Values measured at P1 and $\mathrm{P} 2$ were projected vertically and plotted on the same horizontal axis as those measured at F1-F3, B1 and B2.

suggesting that the relative extent of the shear and compression zones may vary with ploughing velocity. As expected, the spatial extent to which pore pressure rises above the hydrostatic level increases with increasing porepressure magnitude (Fig. 4).

Sub-hydrostatic pore pressures recorded behind the tip (at $\mathrm{P} 2, \mathrm{~B} 1$ and B2) result from the formation of a wake that is devoid of sediment, as observed after an experiment (Rousselot and others, in press). Similar wakes forming behind objects dragged through dry granular material were interpreted as resulting from tensile stresses that cannot be sustained by the cohesionless material (Chehata and others, 2003), implying that the grains do not flow into the wake. Pore-water, however, can flow into this zone devoid of sediment, but in our experiments this is at a rate lower than the velocity of the ploughing tip. Sub-hydrostatic pore pressures are therefore measured behind the tip (Figs 2a and 3b). The absolute magnitudes of these sub-hydrostatic pore pressures are consistently greatest on the tip itself (P2), decrease with increasing distance from the tip (B1, B2) (Fig. 3b) and increase with increasing ploughing velocity (Fig. 4).

No clear influence of the effective normal stress on the pressure measurements at F4, F5, S4, S5, P1, P2, B1 and B2 is observed. In the records of F1-F3, however, the magnitude of the excess pore pressures seems to increase with the applied effective normal stress, probably as a result of a decreasing sediment porosity and thus permeability (Figs 3a and 4).

\section{Shear stress on the tip}

Figure $2 \mathrm{~b}$ shows that the drag force during a ploughing experiment reaches a steady value within a few millimeters of distance ploughed by the tip. Because the magnitude of non-hydrostatic pore pressure is small relative to the applied normal stress and the sediment yield strength, the record of drag force is independent of pore-pressure evolution. The initial, non-zero, value of the drag force results from ploughing carried out before the start of an experiment and reflects the plastic properties of the sediment.
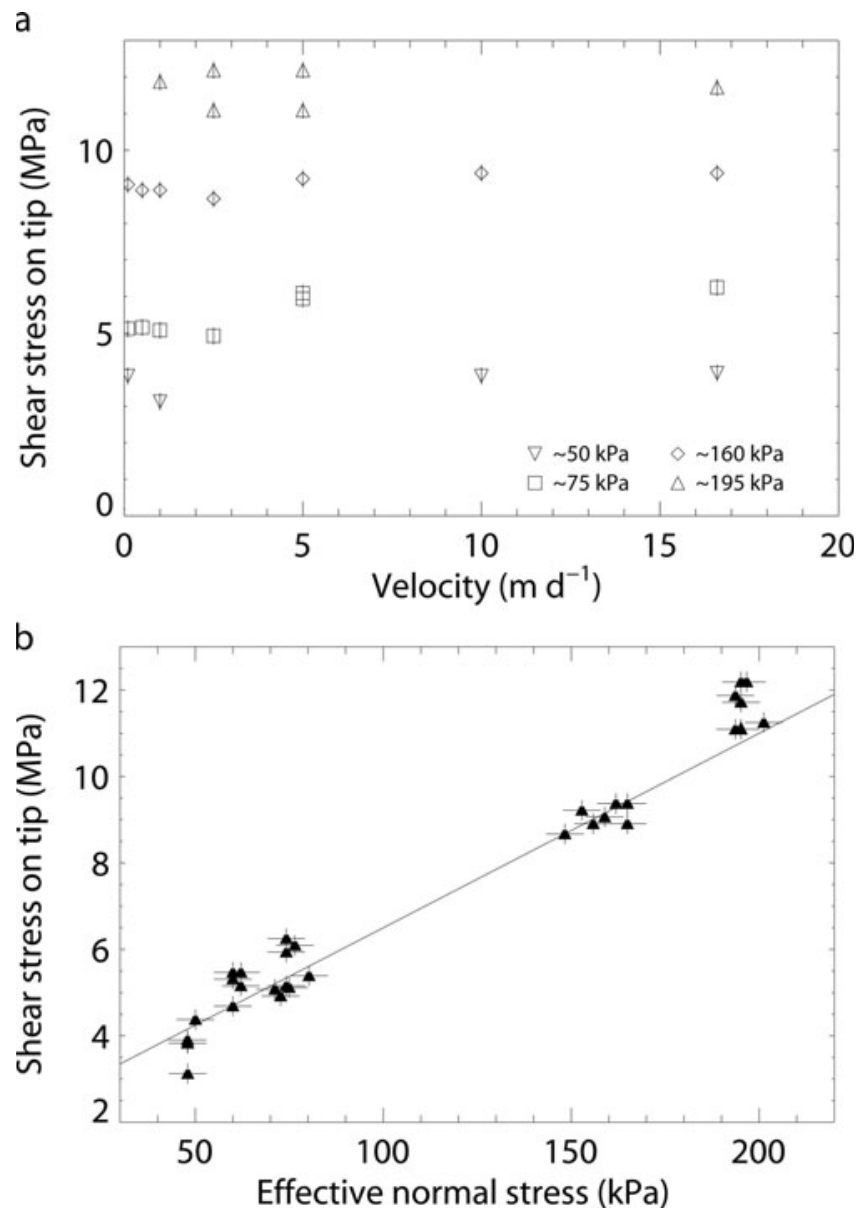

Fig. 5. Shear stress on the ploughing tip as a function of (a) ploughing velocity and (b) applied effective normal stress. The solid line corresponds to the model of Senneset and Janbu (1985) (Equation (5)) shifted in the $y$ direction to overlay the measured data. Justification for this shift stems from the fact that at small effective stresses, below the range considered in this study, real sediment behavior differs from idealized Coulomb behavior in that the friction angle is not constant but tends to increase with decreasing effective stress (Lambe and Whitman, 1979).

For each experiment, the resistive shear stress on the tip was derived from the drag force record. The relationship between the force, $F$, recorded by the ploughing tip and the corresponding force per unit length, $q$, applied by the sediment on the tip can be obtained by equating the bending moments resulting from $F$ and $q$ at the platen. Thus,

$$
q=\frac{2 F}{L}
$$

where $L$ is the length of the tip protruding into the sediment. Substituting the shear stress on the tip $\tau_{\mathrm{t}}=q / 2 a$, where $a$ is the radius of the tip, Equation (1) yields

$$
\tau_{\mathrm{t}}=\frac{F}{\mathrm{aL}} \text {. }
$$

In our experiments, the shear stress on the ploughing tip is seen to be independent of the ploughing velocity, and thus of the rate of sediment deformation, for a given applied effective normal stress (Fig. 5a). Moreover, the shear stress on the ploughing tip increases approximately linearly with the applied effective normal stress (Fig. 5b). These observations are consistent with the Coulomb-plastic rheology of subglacial sediments reported in other studies (Iverson and 
others, 1998; Tulaczyk and others, 2000; Iverson and Iverson, 2001; Kamb, 2001; Kavanaugh and Clarke, 2006).

The geotechnical model of Senneset and Janbu (1985), which was initially developed to express the resistance exerted on cones, piles and plates during vertical insertion into sediment, can be adapted to estimate the shear stress on ploughing objects that are dragged horizontally through sediment (Iverson and others, 1994; Fischer and others, 2001). Accordingly, the shear stress on the moving object, $\tau_{\mathrm{t}}$, scales with the effective stress, $P_{\mathrm{e}}$ in the direction of motion

$$
\tau_{\mathrm{t}}=N_{\mathrm{F}}\left(P_{\mathrm{e}}+\frac{C}{\tan \phi}\right)-\frac{c}{\tan \phi}
$$

where $c$ is the cohesion and $\phi$ is the friction angle of the sediment. $N_{F}$ is a bearing capacity factor, expressed as

$$
N_{\mathrm{F}}=\tan ^{2}\left(\frac{\pi}{4}+\frac{\phi}{2}\right) \mathrm{e}^{(\pi-2 \beta) \tan \phi},
$$

where $\beta$ is the angle of the slip planes in front of the object with a normal to the direction of motion (Senneset and Janbu, 1985). This model was tested experimentally, using dry sediment, by Iverson and others (1994), who suggested that Equation (3) applies to ploughing objects if the sediment is not weakened by local excess pore pressure and may otherwise overestimate the value of $\tau_{\mathrm{t}}$.

We assume the sediment deformed by ploughing is in the residual state with negligible cohesion. Additionally, because the sediment is ploughed prior to an experiment, we can reasonably assume the distribution of effective stresses is isotropic. With these assumptions, Equation (3) reduces to

$$
\tau_{\mathrm{t}}=N_{\mathrm{F}} P_{\mathrm{e}} \text {. }
$$

Hence, taking the sediment friction angle of $35^{\circ}$, we find from Senneset and Janbu (1985) that $N_{\mathrm{F}} \sim 45$ for the dense coarse-grained sediment used in our experiments $\left(\beta \sim-15^{\circ}\right)$. The model generally compares well with our data (Fig. 5b), but possibly slightly underestimates the increase in shear stress with increasing effective stress. This suggests that for large applied effective normal stresses the overconsolidated sediment in front of the tip is denser than assumed in the theory.

\section{DISCUSSION}

Our ploughing experiments suggest that the distribution of water pressure around the ploughing tip results from three distinct effects. Pore pressures above and below the hydrostatic value are due to sediment compression and dilatant shearing, respectively, and water pressure below the hydrostatic value develops as a result of a sediment-free wake left behind the tip. As the applied effective normal stress is constant in our experiments, the spatial changes in pore pressure around the tip are likely to cause spatial variations in the local effective stress, and thus in the sediment yield strength. Therefore, the shear stress on the ploughing tip may be influenced simultaneously by sediment that is weakened in front of the tip due to sediment compression and strengthened in regions of dilatant shearing. The motion of the tip may be resisted additionally by the drag force associated with the water-pressure gradient that develops between the front and back of the tip. However, unlike the magnitude of the pore pressures, the magnitude of the shear stress on the tip is independent of the ploughing velocity. Furthermore, although in some experiments excess pore

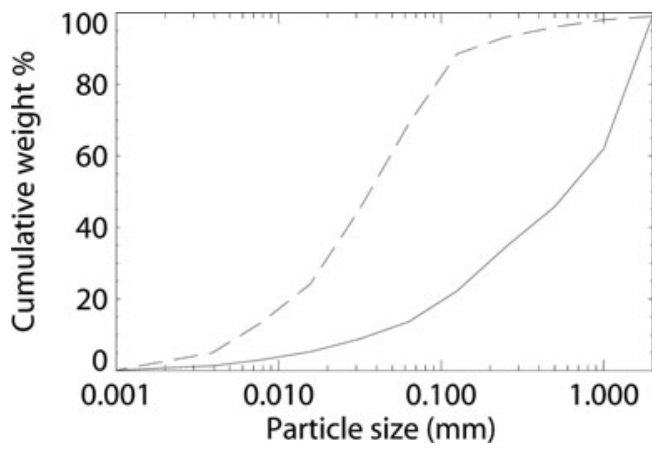

Fig. 6. Comparison of the grain-size distribution of sediments collected in the forefield (solid line) and sampled at the base of a borehole (dashed line, Theiler, 2002) at Unteraargletscher.

pressure reduced the effective stress locally by up to $10 \%$, our records of shear stress on the tip agree roughly with values predicted by the model of Senneset and Janbu (1985), which assumes that the sediment is not weakened by local excess pore pressure. These results indicate that the shear stress on the tip is not significantly influenced by the pore pressure. As observed in our experiments, the spatial extent to which pore pressure rises above the hydrostatic level increases with increasing pore-pressure magnitude (Fig. 4). It is therefore possible that the magnitude of the excess pore pressure generated during ploughing of Unteraargletscher sediment is too small to influence a significant volume of sediment. Alternatively, although sediment weakening may affect a large volume of sediment, it may be simultaneously counterbalanced by the drag due to the pore-pressure gradient across the tip and sediment strengthening in regions of dilatant shearing. Such dilatant strengthening of subglacial sediment has been observed in laboratory experiments by Moore and Iverson (2002). However, we note that our porepressure measurements are spatially too sparse to conclusively quantify the relative influence of pore pressures above and below hydrostatic on overall ploughing resistance.

The results of our laboratory measurements differ from those of a field study conducted at Unteraargletscher, where pore-water pressure in front of an object pulled through subglacial sediment and water pressure at the base of a borehole were recorded simultaneously (Rousselot and Fischer, 2005). Analysis of the field data indicated that excess pore pressure developed directly in front of the object, a finding which contradicts that of the present study, where a pore pressure below the hydrostatic value was measured on the leading edge of the ploughing tip (at P1). Comparison of the grain-size distribution of a sediment sampled at the base of a borehole near the measurement site (Theiler, 2002) with that collected in the forefield of the glacier for the laboratory experiments reveals that the sediment from beneath the glacier contains a greater proportion of fine particles (Fig. 6). A sediment with a larger proportion of fine particles is likely to have a smaller diffusivity (e.g. Freeze and Cherry, 1979) and thus to promote the generation of excess pore pressure as it is compressed (e.g. Lee and Bobet, 2005). We therefore suggest that the excess pore pressure generated a few centimeters in front of the object dragged through the sediment beneath Unteraargletscher was larger than that measured at, for example, F2 in our laboratory device. This large excess pore pressure may have affected the region 
directly in front of the object by raising the pore pressure to a value above hydrostatic, although a pressure below the hydrostatic level is expected there due to shear-induced sediment dilation. This idea is supported by the results of a geotechnical study of Finke and others (2001), where a cone was inserted vertically into a soil at different penetration rates. For a standard penetration rate, pore pressure above and below the hydrostatic value were recorded on the face and shoulder of the cone, respectively. For a penetration rate ten times higher, the reading of pore pressure above the hydrostatic value on the face increased while excess pore pressure was also measured on the shoulder.

Theories from soil mechanics may provide an alternative explanation for the contrasting pore-pressure records from the field and the laboratory. According to these, a sediment may increase or reduce its volume during shearing depending on its initial porosity. If the initial porosity is below the value corresponding to the critical state, the sediment will dilate; conversely, if the initial porosity is larger than the value corresponding to the critical state, it will contract (Lambe and Whitman, 1979). However, the porosity of an overconsolidated sediment is not necessarily below the critical value (e.g. Wood, 1990), in particular for an initially loose sediment. The excess pore pressure that developed directly in front of the object dragged through the bed beneath Unteraargletscher may therefore have been caused by the reduction of pore volume of the overconsolidated sediment in the compression zone that was sheared by the object.

Our results also contrast significantly with those of Thomason and Iverson (2003), who used a ring-shear device to drag hemispheres through water-saturated subglacial sediment. In their experiments, the shear stress on the hemispheres decreased with increasing velocity as a result of sediment weakening due to excess pore-pressure generation. The potential for the generation of excess pore pressure as a sediment is compressed depends inversely on the sediment diffusivity and directly on the ploughing velocity and the diameter of the ploughing object (Iverson and LaHusen, 1989; Iverson and others, 1994; Iverson, 1999; Fischer and others, 2001). The ploughing experiments of Thomason and Iverson (2003) were performed at velocities one order of magnitude smaller than those in our experiments, using hemispheres with diameters similar to that of the ploughing tip. Therefore, the large excess pore pressures measured in front of the hemispheres were likely to have been promoted primarily by the low diffusivity of the sediment used in the experiments $\left(8.7 \times 10^{-9} \mathrm{~m}^{2} \mathrm{~s}^{-1}\right.$; four orders of magnitude less than that of the Unteraargletscher sediment used in this study). These large excess pore pressures probably influenced significant volumes of sediment, including regions of shear-induced dilation, so that the shear stress on the hemisphere was reduced considerably. It is conceivable that for higher ploughing velocities (which would exceed values typical for glaciers) significant excess pore pressure would also develop in the sample of Unteraargletscher sediment used in our experiments.

\section{CONCLUSION}

In this study, a new laboratory device was used to investigate the implications of clast ploughing for the basal motion of glaciers. Specifically, the hypothesis was tested that the generation of excess pore pressure in front of a ploughing object may locally reduce the sediment yield strength significantly (Iverson, 1999; Fischer and others, 2001; Thomason and Iverson, 2003). The results of ploughing experiments performed with a sediment of high diffusivity showed that the distribution of pore pressure around a ploughing object is more complex than previously believed (Iverson and others, 1994; Fischer and others, 2001), with pore pressures above and below the hydrostatic value. The resistive shear stress on the ploughing object was not significantly influenced by these pore pressures, but was proportional to the applied effective normal stress and independent of the ploughing velocity, in agreement with a Coulomb-plastic rheology of the sediment.

Our results, when compared to those of other studies (Thomason and Iverson, 2003), suggest that the degree of sediment weakening in front of ploughing clasts may depend on the relative magnitudes of excess pore pressure generated by sediment compression and sub-hydrostatic pore pressure due to dilatant shearing. For typical glacier velocities and sizes of ploughing clasts, these magnitudes are likely to be governed by the diffusivity and the density of the sediment, respectively. Moreover, large excess pore pressure may affect the yield strength of a sediment, not only in regions of sediment compression but also in regions of dilatant shearing. This effect may occur preferentially at the base of fast-flowing glaciers underlain by sediment of low diffusivity. The resulting positive feedback between increasing ploughing speed and decreasing shear stress on ploughing clasts may have the potential to trigger flow instabilities such as glacier surging or fast ice streaming (Thomason and Iverson, 2003). In contrast, if sub-hydrostatic pore pressure develops over large areas of the bed during clast ploughing, the subglacial sediment may be significantly strengthened. In this case, since the magnitude of the pore-pressure decrease depends on the shear rate of the sediment, the resistive shear stress on the clast may be directly proportional to the sliding velocity. Clast ploughing may therefore induce local pseudoviscous behavior of the sediment and act to stabilize the motion of glaciers underlain by dense dilatant sediment. If subsequent sediment weakening, resulting from the equilibration of the pore pressure, occurs, fast motion of the glacier may be re-initiated (Moore and Iverson, 2002). This effect, analogous to the regulation of landslide motion described by Iverson (2005), may result in stick-slip motion of glaciers.

\section{ACKNOWLEDGEMENTS}

This work was funded by ETH grant TH-7/01-1. We thank M. Pfister for the design of the support frame, and the VAW workshop staff for the construction of the rotary ploughing device. We are grateful to T. Wyder who kindly helped during the ploughing experiments. Generous assistance with the set-up of the experiments was also provided by B. Nedela, S. Gribi, D. Gubser, A. Pralong and M. Raymond. Logistical support was kindly provided by the Centro Stefano Francini, ETH-Zürich. We also thank J. Kavanaugh and J. Thomason for insightful review comments, the scientific editor N. Glasser for handling this paper and N. Iverson for his review of an earlier version of the manuscript.

\section{REFERENCES}

Alley, R.B. 1989. Water-pressure coupling of sliding and bed deformation: II. Velocity-depth profiles. J. Glaciol., 35(119), 119-129. 
Alley, R.B., D.D. Blankenship, C.R. Bentley and S.T. Rooney. 1987. Till beneath Ice Stream B. 3. Till deformation: evidence and implications. J. Geophys. Res., 92(B9), 8921-8929.

Alley, R.B., S. Anandakrishnan, T.K. Dupont and B.R. Parizek. 2004. Ice streams - fast, and faster? C. R. Physique, 5(7), 723-734.

Boulton, G.S. and R.C.A. Hindmarsh. 1987. Sediment deformation beneath glaciers: rheology and geological consequences. J. Geophys. Res., 92(B9), 9059-9082.

Brown, N.E., B. Hallet and D.B. Booth. 1987. Rapid soft bed sliding of the Puget glacial lobe. J. Geophys. Res., 92(B9), 8985-8997.

Chehata, D., R. Zenit and C.R. Wassgren. 2003. Dense granular flow around an immersed cylinder. Phys. Fluids, 15(6), 1622-1631.

Finke, K.A., P.W. Mayne and R.A. Klopp. 2001. Piezocone penetration testing in Atlantic piedmont residuum. J. Geotech. Geoenviron. Eng., 127(1), 48-54.

Fischer, U.H. and G.K.C. Clarke. 1994. Ploughing of subglacial sediment. J. Glaciol., 40(134), 97-106.

Fischer, U.H., P.R. Porter, T. Schuler, A.J. Evans and G.H. Gudmundsson. 2001. Hydraulic and mechanical properties of glacial sediments beneath Unteraargletscher, Switzerland: implications for glacier basal motion. Hydrol. Process., 15(18), 3525-3540.

Freeze, R.A. and J.A. Cherry. 1979. Groundwater. Englewood Cliffs, NJ, Prentice Hall.

Harrison, W.D. and A.S. Post. 2003. How much do we really know about glacier surging? Ann. Glaciol., 36, 1-6.

Iverson, N.R. 1999. Coupling between a glacier and a soft bed. II. Model results. J. Glaciol., 45(149), 41-53.

Iverson, R.M. 2005. Regulation of landslide motion by dilatancy and pore pressure feedback. J. Geophys. Res., 110(F2), F02015. (10.1029/2004JF000268.)

Iverson, N.R. and R.M. Iverson. 2001. Distributed shear of subglacial till due to Coulomb slip. J. Glaciol., 47(158), 481-488.

Iverson, R.M. and R.G. LaHusen. 1989. Dynamic pore-pressure fluctuations in rapidly shearing granular materials. Science, 246(4931), 796-799.

Iverson, N.R., P. Jansson and R.LeB. Hooke. 1994. In-situ measurement of the strength of deforming subglacial till. J. Glaciol., 40(136), 497-503.

Iverson, N.R., B. Hanson, R.LeB. Hooke and P. Jansson. 1995. Flow mechanism of glaciers on soft beds. Science, 267(5194), 80-81.

Iverson, N.R., T.S. Hooyer and R.W. Baker. 1998. Ring-shear studies of till deformation: Coulomb-plastic behavior and distributed strain in glacier beds. J. Glaciol., 44(148), 634-642.

Kamb, B. 2001. Basal zone of the West Antarctic ice streams and its role in lubrication of their rapid motion. In Alley, R.B. and R.A. Bindschadler, eds. The West Antarctic ice sheet: behavior and environment. Washington, DC, American Geophysical Union, 157-199. (Antarctic Research Series 77.)
Kavanaugh, J.L. and G.K.C. Clarke. 2006. Discrimination of the flow law for subglacial sediment using in situ measurements and an interpretation model. J. Geophys. Res., 111(F1), F01002. (10.1029/2005JF000346.)

Lambe, T.W. and R.V. Whitman. 1979. Soil mechanics. New York, etc., John Wiley and Sons.

Lang, H.J., J. Huder and P. Amann. 2003. Bodenmechanik and Grundbau: das Verhalten von Boden und Fels und die wichtigsten grundbaulichen Konzepte. Seventh Edition. Berlin, etc., Springer-Verlag.

Lee, H. and A. Bobet. 2005. Laboratory evaluation of pullout capacity of reinforced silty sands in drained and undrained conditions. Geotech. Test. J., 28(4), 370-379.

Moore, P.L. and N.R. Iverson. 2002. Slow episodic shear of granular materials regulated by dilatant strengthening. Geology, 30(9), 843-846.

Ó Cofaigh, C. and 6 others. 2005. Flow dynamics and till genesis associated with a marine-based Antarctic palaeo-ice stream. Quat. Sci. Rev., 24(5-6), 709-740.

Rousselot, M. and U.H. Fischer. 2005. Evidence for excess porewater pressure generated in subglacial sediment: implications for clast ploughing. Geophys. Res. Lett., 32(11), L11501. (10.1029/ 2005GL022642.)

Rousselot, M., U.H. Fischer and M. Pfister. In press. A new laboratory apparatus for investigating clast ploughing. In Hambrey, M., N. Glasser, P. Janssen, B. Hubbard, P. Christoffersen and M. Siegert, eds. Glacial sedimentary processes and products. Oxford, Blackwell.

Senneset, K. and N. Janbu. 1985. Shear strength parameters obtained from static cone penetration tests. In Chaney, R.C. and K.R. Demars, eds. Strength testing of marine sediments: laboratory and in-situ measurements. Philadelphia, PA, American Society for Testing and Materials, 41-54. (Special Technical Publication 883.)

Theiler, A. 2002. Strukturen von subglazialen Sedimenten. (Undergraduate thesis, ETH-Zürich.)

Thomason, J.F. and N.R. Iverson. 2003. Flow mechanism of ice sheets on unlithified sediment: plowing of clasts at the ice-bed interface. Geol. Soc. Am. Abstr., Ann. Meet. Suppl., 35(6), Abstr. 122-9.

Truffer, M., K.A. Echelmeyer and W.D. Harrison. 2001. Implications of till deformation on glacier dynamics. J. Glaciol., 47(156), 123-134.

Tulaczyk, S.M., B. Kamb and H.F. Engelhardt. 2000. Basal mechanics of Ice Stream B, West Antarctica. II. Undrainedplastic-bed model. J. Geophys. Res., 105(B1), 483-494.

Van der Meer, J.J.M., ed. 1987. Tills and glaciotectonics. Rotterdam, A.A. Balkema.

Wood, D.M. 1990. Soil behaviour and critical state soil mechanics. Cambridge, Cambridge University Press. 